\title{
Occupant behavior modeling for building performance simulation: current state and future challenges
}

\author{
Da YAN ${ }^{a} *$, William O’BRIEN ${ }^{b}$, Tianzhen HONG ${ }^{c}$, Xiaohang FENG ${ }^{a}$, H. Burak GUNAY ${ }^{b}$, Farhang TAHMASEBI ${ }^{d}$, \\ Ardeshir MAHDAVI ${ }^{\text {d }}$ \\ ${ }^{\text {a }}$ School of Architecture, Tsinghua University, Beijing 100084, China \\ Email address: yanda@tsinghua.edu.cn (D. Yan) fengxh12@mails.tsinghua.edu.cn (X. Feng) \\ *Corresponding author. Tel: +86106278 9761; Fax: +86 106277 0544; \\ ${ }^{\mathrm{b}}$ Department of Civil and Environmental Engineering, Carleton University, 1125 Colonel by Drive Ottawa, \\ ON K1S 5B6, Canada \\ Email address: Liam.OBrien@carleton.ca (W. O’Brien), hgunay@connect.carleton.ca (H.B. Gunay) \\ ' Lawrence Berkeley National Laboratory, 1 Cyclotron Road, Berkeley, California 94720, USA \\ Email address: thong@LBL.gov (T. Hong) \\ ${ }^{d}$ Department of Building Physics and Building Ecology, Vienna University of Technology, A-1040 Vienna, \\ Austria \\ Email address: farhang.tahmasebi@tuwien.ac.at (F.Tahmasebi), amahdavi@tuwien.ac.at (A. Mahdavi)
}

\begin{abstract}
Occupant behavior is now widely recognized as a major contributing factor to uncertainty of building performance. While a surge of research on the topic has occurred over the past four decades, and particularly the past few years, there are many gaps in knowledge and limitations to current methodologies. This paper outlines the state-of-the-art research, current obstacles and future needs and directions for the following four-step iterative process: (1) occupant monitoring and data collection, (2) model development, (3) model evaluation, and (4) model implementation into building simulation tools. Major themes include the need for greater rigor in experimental methodologies; detailed, honest, and candid reporting of methods and results; and development of an efficient means to implement occupant behavior models and integrate them into building energy modeling programs.
\end{abstract}

Keywords: Occupant behavior, energy modeling, building simulation, energy efficiency, energy use

\section{Introduction}

Building energy consumption accounts for $30 \%$ of the global energy consumption revealing a great potential for energy conservation [IEA, 1]. To address this issue, building simulation is gaining widespread application as a cost-effective method to support energy efficient design and operation of buildings. Building simulation includes the evaluation of the performance of architectural concepts, HVAC systems, or energy-saving approaches and technologies. The International Energy Agency (IEA), Energy in the Buildings and Communities Programme (EBC), Annex 53: Total Energy Use in Buildings, identified (1) climate, (2) building envelope, (3) building energy and services systems, (4) indoor design criteria, (5) building operation and maintenance, and (6) occupant behavior, as the driving factors of energy use in buildings. While there has been significant progress in the first five focus areas, there lacks scientific and robust methods to define and model energy related occupant behavior in buildings. These behaviors include occupants' interactions with operable windows, lights, blinds, thermostats, and plug-in appliances. The importance of the 
"human factor" in building performance simulation is evident [2-4]. In short, occupant behavior affects building energy consumption significantly and is a leading source of uncertainty in predicting building energy use [5].

Due to the significant uncertainty of building model inputs, simulation results sometimes deviate widely from the actual energy consumption of a building. Figure 1 shows a comparison between the simulated (predicted) energy consumption modeled during the design phase and the measured energy consumption for 62 Leadership in Energy and Environmental Design (LEED) certified buildings in the United States. For some buildings, models are relatively good predictors of the actual building performance. Nevertheless, there is a normalized root-mean-squared error of $18 \%$.

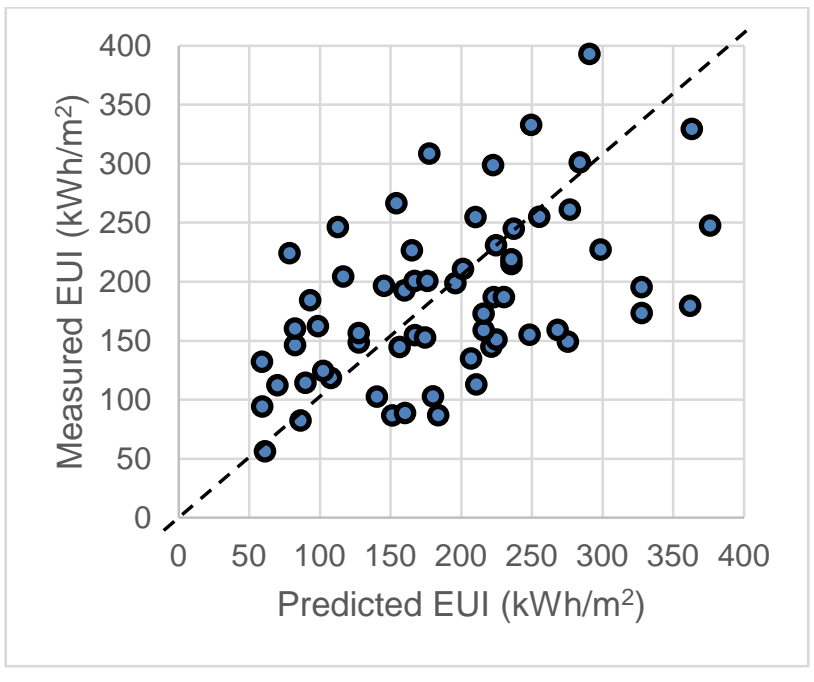

Figure 1: Comparison of measured and predicted energy use for 62 LEED New Construction buildings (modified from Turner, et al. [6])

To illustrate the impact of the uncertainty occupant behavior has on energy use, consider a study where Li, et al. [7] investigated the cooling electricity use in 25 households in a large residential building in Beijing during a summer. The results are shown in Figure 2.

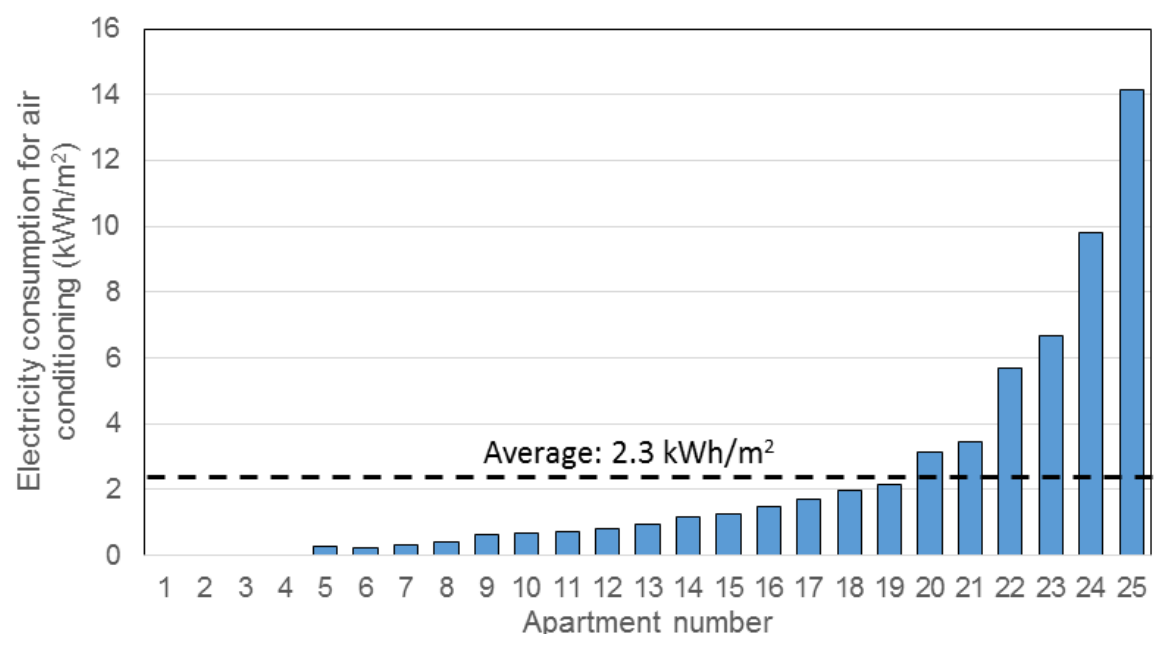

Figure 2: Measured air conditioning electricity consumption per unit floor area in the summer in a residential building in Beijing (modified from Li, et al. [7])

With an identical building envelope, the measured electricity consumption for air-conditioning in different apartments varied widely. The discrepancy was caused by the operating mode of the split-type air conditioning (AC) system. An apartment where the occupant kept the air conditioning on for longer 
durations or in larger spaces consumed more energy than an apartment using the AC for a shorter period of time and/or in smaller spaces. Thus, the occupant is the driver of the energy use, rather than the design of the apartments.

Clevenger and Haymaker [8] studied uncertainty in occupant behavior in building energy models, using various occupancy schedules and environmental preferences and found that the energy consumption differed $150 \%$ (or more) if the occupant-related inputs were maximized and minimized (even for typical occupant behavior patterns). Guerra Santin, et al. [9] studied the influence of occupant behavior on heating, and found that the way occupants used the heating system made a significant difference on heating energy consumption. It can be concluded that occupants' presence and interaction with various building components significantly affect the energy consumption predictions made by energy simulation, even if the weather conditions, the building envelope, and the equipment are well-defined.

Occupant behavior is a key factor in the evaluation of technologies used in building design and retrofit. Case studies have demonstrated that occupant behavior influences the adaptability and implementation of building technologies. For example, Fabi, et al. [10] studied the robustness of building design with different operations of windows and movable shadings, and found that a description of occupant behavior will result in robust building designs. Belessiotis and Mathioulakis [11] reported that the energy savings potential, by increasing building insulation, depends heavily on occupants' use of terminal heating systems. Understanding the interactions between occupant behavior and building technologies are critical to improving building design and operation. Different occupant behavior patterns require corresponding technical solutions, which may induce or alter behavior patterns. More important than the technology efficiency is the effective interaction between occupants and building systems to achieve their comfort and health needs.

Occupants undertake behaviors that can be modeled stochastically [12, 13]; meaning that occupants' presence and behavior patterns not only vary between each other, but also tend to evolve in time. For example, occupants' behavior may differ due to the individual variance of environmental perception. Reinhart and Voss [14], by monitoring lighting control in ten offices, found that the workplane illuminance levels triggering a light switch action varied significantly from one individual to another. Similarly, Galasiu and Veitch [15] found that an individual's preferred work plane illuminance ranged from 230 to 1000 lux. AlMumin, et al. [16] investigated summer air-conditioning use in residential buildings, and concluded that the thermostat setpoint could vary from below $19^{\circ} \mathrm{C}$ to above $25^{\circ} \mathrm{C}$. Brager, et al. [17] observed that identical thermal conditions can lead to both window opening and closing in different offices.

Occupant behavior is a complicated mechanism and influenced by multiple contextual factors. Research carried out by Warren and Parkins [18] indicated that the primary factor motivating occupants to open windows in the winter is the indoor air quality. While in the summer noise from outside was reported to be the primary factor leading a window closing action. Other factors leading to window operation include indoor humidity [19] and weather conditions (e.g., windy or rainy [20]). Mahdavi [2] observed a relationship between closing shades and the magnitude of vertical irradiance, but opening shades did not reveal a clear relationship to the amount of incident solar radiation. Sociological or psychological factors also contribute to influencing occupant behavior. Zhang and Barrett [21] studied the factors influencing blind operation in a naturally ventilated building, and reported that the desire to maintain view and connection to outdoors drove occupants to open the blinds. Whereas, Foster and Oreszczyn [22] suggest that occupants in offices which face other buildings tend to keep the blinds down for privacy reasons. 
Occupants in building simulation tools are conventionally represented in terms of static schedules [5]. This simplification does not properly model the complex influence of occupant behavior on building energy consumption and the indoor environment $[23,24]$. In reality, there should be a dynamic interaction between a building and its occupants so that more sustainable designs can be identified. For example, without modeling occupant use of window blinds, simulation results may indicate that maximizing the window area will lead to maximized daylight utilization. However, in reality, very large windows may merely prompt occupants to close blinds and exclusively rely on electric lighting due to glare issue. Evidently, the use of static schedules to represent occupant behavior in building simulation tools fails to reflect this dynamic interaction between the users and a building's design. To mimic the dynamic interactions between a building and its occupants, several dozen occupant behavior models have been developed based on longterm observational studies [25]. Several stochastic models have been developed to describe window operations [26-31], blinds [21, 32-35] and lighting [33, 36-38]. Other behaviors such as operation of airconditioning [39, 40] and clothing adjustment [41] have been studied less. These models typically require large amounts of data to establish a statistical relationships between the environmental factors and the targeted operation(s). However, these models barely scratch the surface considering the requirement for the numerous building typologies, cultures, climates, etc.

Occupants' movements and presence are fundamental to occupant behavior simulation by providing information about whether a room is occupied, the number of occupants, or the specific individual in the room. The real occupancy patterns in buildings may differ significantly from each other. For example, Mahdavi, et al. [42] observed highly inter-individual differences in occupancy patterns while studying shading and lighting operation in four office buildings in Austria. Realistic representation of occupancy becomes important considering occupants generate indoor air contaminants, sensible and latent heat, and their presence affects operational controls (lights, blinds, plug loads, etc.). Furthermore, arrival, departure, and duration of absence have been found to be influential factors affecting occupant-building interaction [33, 34, 42]. Chang and Hong [43] analyzed data collected from 200 cubicle offices on three floors of a commercial office building and developed a model to describe the occupancy patterns. Within Chang and Hong [43] model, probability distributions of the number of absences and the absence durations were assessed. The model developed by Page et al. [44] generated a time series of the state of presence (absent or present) of each occupant of a space, for each space of a building, by considering occupant presence as an inhomogeneous Markov chain interrupted by occasional periods of long absence. Wang, et al. [45] proposed an approach for building occupancy simulation based on Markov chains. Each occupant was associated with a homogenous Markov matrix to simulate the stochastic movement process. These models all treat occupancy as a stochastic process with certain statistical laws described by the model. Each modeling approach represents the stochastic nature differently, using unique algorithms.

The remaining part of the paper is comprised of a technical framework and four major sections: (1) data collection, (2) model development, (3) model verification, and (4) model implementation into simulation tools. These sections review the current state-of-the-art while identifying future research needs. Many of the research needs will be addressed by the large group of researchers involved in International Energy Agency Energy in Buildings and Communities Program (IEA EBC) Annex 66: Definition and Simulation of Occupant Behavior in Buildings. 


\section{Technical framework}

Due to the complexity and uncertainty of an individual occupant, the complete mechanism of occupant behavior influenced by physical, physiological, psychological and other factors, is difficult to thoroughly study within the building simulation field. The modeling of occupant behavior in building simulation is narrowed down to a simplified representation that is still sophisticated enough to quantify occupants' impact on building performance and the impact of buildings on occupants. The focus of the current paper is occupant behavior, movement, and action portion of Figure 3. Nevertheless, these topics cannot be researched in isolation, without understanding of the broader issues such as human psychology and physiology.

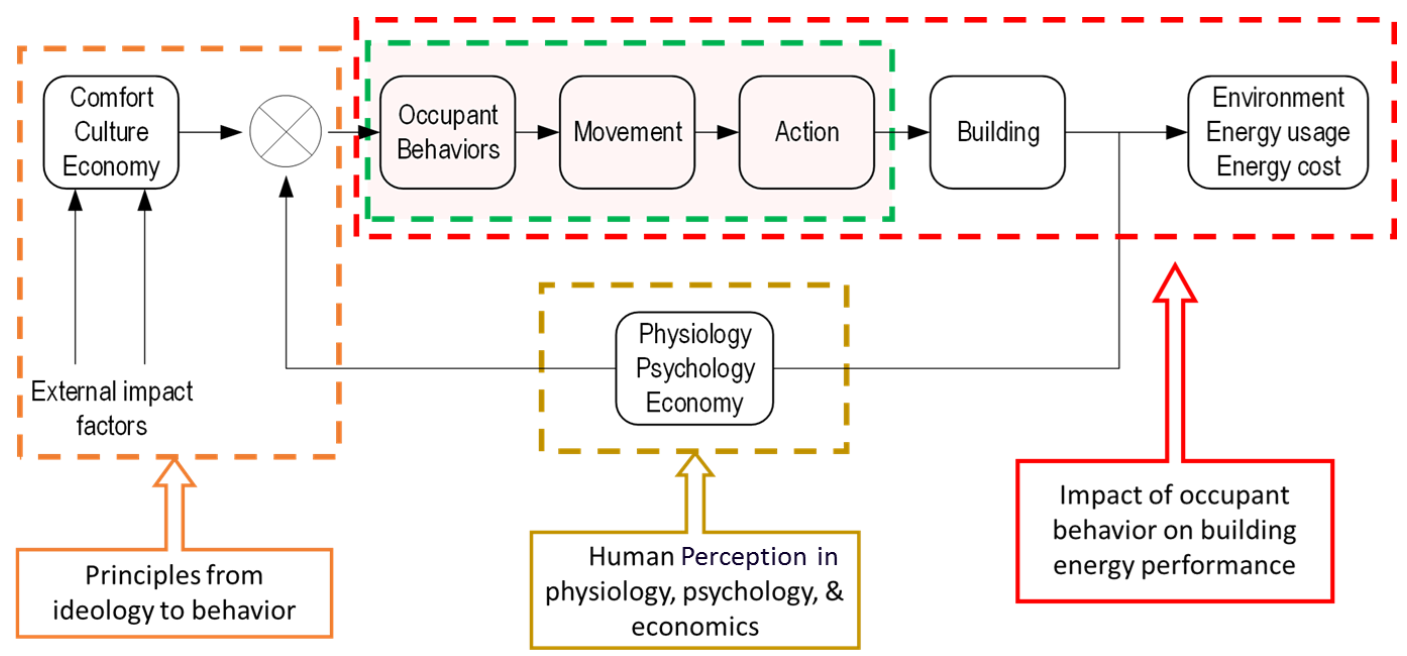

Figure 3: Scope of occupant behavior research in building simulation [46]

In current modeling practice, researchers commonly follow the technical approach illustrated in Figure 4. Data about occupant behavior and possibly environmental conditions are collected. They are then used for quantitative analysis in the modeling part to obtain correlations between indoor and outdoor environmental conditions and/or events and behaviors within a set of contextual factors. In order to verify that the developed models are reliable and effective, a rigorous model evaluation should be performed. Finally, the behavior models can be implemented and integrated within simulation tools for designers and researchers to use. It is worth noting that the process is not once-through but iterative. For instance, upon model development or evaluation, it may be found that insufficient data were collected. Similarly, a developed model may prove to be impractical for implementation into a simulation tool if the model inputs are not readily available. In short, if problems are revealed during a given stage, the researcher may have to step back and re-iterate. 


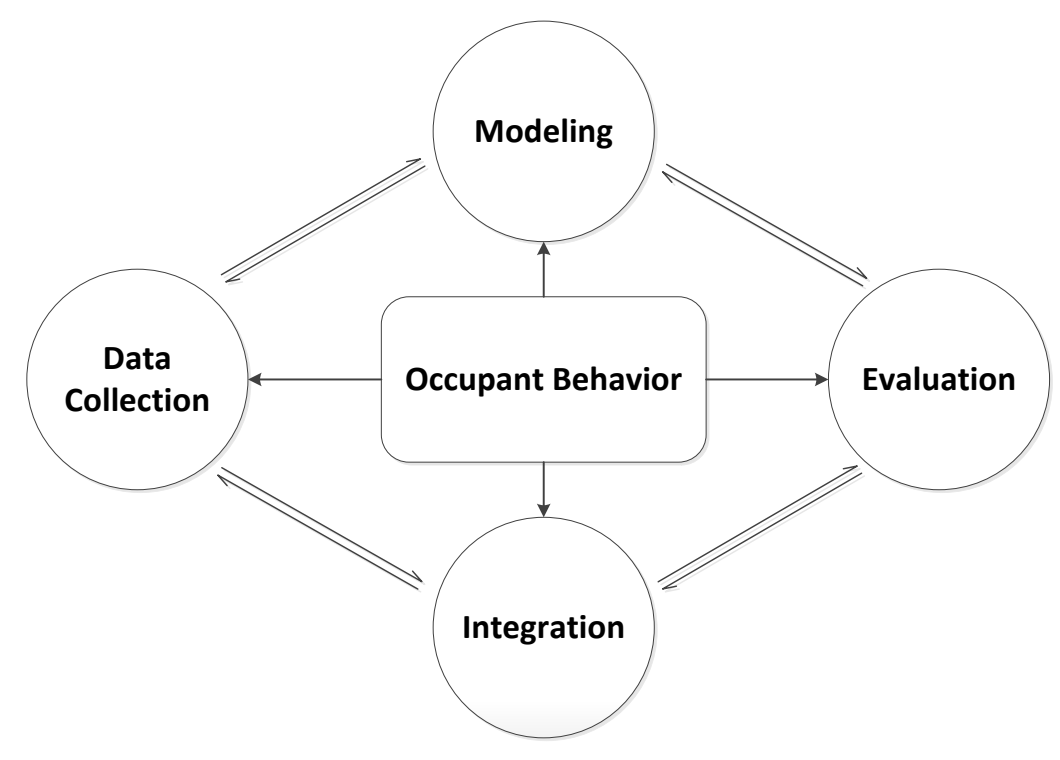

Figure 4: Technical framework of occupant behavior modeling and simulation

\section{Methods and procedures for occupant monitoring and data collection}

Because we want occupant models to have a realistic basis rather than to make unfounded assumptions about how we would expect occupants to behave, occupant models are developed upon observational data. Existing research includes numerous data collection approaches including non-invasive occupant observations, observing occupants that have had perturbations applied, surveys, and laboratory studies. Hence, the occupant monitoring approaches were first divided in three main categories: (a) observational studies, (b) surveys and interviews, (c) laboratory studies. After discussing the advantages and shortcomings with regards to accuracy, effort, and ethical considerations, unresolved issues in occupant monitoring studies were identified and future research recommendations were developed.

\subsection{Observational studies}

In observational studies, the occupants' behavior and presence and indoor environmental variables are passively monitored. Because occupants rarely interact with some of the building components (e.g., blinds [47]) and these interactions may exhibit seasonal variations (e.g., windows [26]), the monitoring periods to gather data to develop and verify an occupant model typically extend over at least numerous months. Also, the selection and placement of sensors to monitor occupant interacting building components and presence can play an unprecedented role over the way occupants exhibit behavioral patterns.

This subsection divides the observational studies in two groups: (a) occupancy and equipment use monitoring and (b) adaptive behavior monitoring. The discussion on occupancy and plug-in appliances (non-HVAC) are grouped together here because both phenomena can be considered building designindependent (though building design could have a minor effect on absenteeism [48]). In contrast, monitoring adaptive behaviors (e.g., light switch on or blinds closing) also requires the monitoring of the environmental variables as candidate predictors for the adaptive behavior models.

\subsubsection{Occupancy and equipment use monitoring}

Accurate occupancy detection remains a challenge. Occupancy detection approaches in the literature include motion detectors (e.g., passive infrared and ultrasonic), carbon dioxide sensors, video cameras with computer vision, wearable sensors, security-based systems, and diaries $[49,50]$. Motion detectors are the 
dominant form of occupancy sensors [50], but they are unable to detect nearly-motionless occupants, as is typical in offices or sedentary activities in homes. However, they can reliably identify the occupancy state transitions at arrival (e.g., the first passive infrared (PIR) sensor detection of the day), at departure (e.g., the last PIR sensor detection of the day), and long intermediate vacancy periods.

A few researchers [51-53] demonstrated that coupling motion detectors and carbon dioxide could improve occupancy detection accuracy, though there is a significant delay between occupancy and $\mathrm{CO}_{2}$ increase. Furthermore, this method is difficult in open areas or spaces with multiple sources and sinks for $\mathrm{CO}_{2}$ (e.g., an open-plan or naturally ventilated office) [50]. On the contrary, Hailemariam, et al. [54] reported that the inclusion of other sensor types beyond PIR motion sensors did not improve overall occupancy detection accuracy; this was interpreted as the error propagating from different sensor types can undermine the accuracy of occupancy detections [55].

Cameras have been used by researchers to attempt to both identify occupancy and count the number of occupants. Knowledge of the number of occupants is important because presence of multiple occupants is known to impact behavior [34]. Trivedi, et al. [56] showed that this could be done with reasonably high accuracy using computer vision techniques. However, this is a computationally-intensive approach, has significant cost and privacy implications [50]. Several recent reviews have explored the potential to use wearable sensors, mobile devices, and security systems to detect occupancy, identify occupants [57, 58]. These are likely to be an important tool in occupant behavior research.

Equipment (i.e., plug loads except HVAC) in homes and offices represents substantial uncertainty because both the type of appliance and use patterns are not usually controlled by the building designer or operator. Some exceptions to this are hotels and university residences, where appliances are often standardized. Plug loads can represent over $20 \%$ of total building energy use with reported uncertainties between occupants or households as high as a factor of $400 \%$ [e.g., 59]. Plug loads not only use electricity but also generate heat which has heating and cooling implications. Behaviors related to water use should not be neglected since they affect both water use and water heating energy.

A primary methodological issue posted by researchers who are performing plug load monitoring studies is the spatial resolution. That is, what is the necessary disaggregation of the plug loads? Submetering plug loads for multiple buildings or spaces is an expensive endeavor. Numerous plug-level meters that can send data wirelessly to a central hub are available, though deployment is time-consuming. Therefore, there have been tremendous effort to develop load disaggregation algorithms that can identify individual loads (i.e., systematically measuring individual loads) $[60,61]$.

\subsubsection{Adaptive occupant behavior monitoring}

Major behaviors of interest include light-switching, window blind-adjusting, window-opening, thermostatadjusting, clothing level-choice and adjustment, fan use, and door use. The section is organized by discussing each of the adaptive actions, and finally the environmental variables that are used to predict them. Focus is on practical issues and issues specific to buildings, since there is considerable existing knowledge on sensor accuracy, precision, and calibration.

Early on, comprehensive monitoring campaigns were identified as being time-consuming, expensive, and prone to inaccuracies [e.g., 62]. Manual observation methods (e.g., photographic or manual recording) posed a limitation on sample size - both number of occupants and duration - and did not lend themselves to developing statistical models that are suitable for building simulation. They were nevertheless valuable for identifying key behaviors and motivators. More recently this process has been automated by several 
researchers $[63,64]$. A more robust observation method is to electronically collect data about occupant interaction with motorized blinds. However, motorized blinds are known to be used more frequently than manual blinds [65]. Thus blinds use models developed from motorized blinds should ideally be restricted to other buildings with this configuration - not ones with manual blinds. Arguably the least labor intensive method to monitor blinds would be to use contact or proximity sensors, though their use has not been reported by the literature. Monitoring partial opening/closing events and positions is critical because daylight adequacy in not linearly related to blind position (e.g., a blind that is just partly open may still provide ample daylight). Another major gap in the literature is venetian blind slat angle adjustment. Daylight transmission is highly sensitive to slat angle and can be vastly different for blinds that are sloped downwards versus upwards. The solution to use two cameras at different angles of altitude, both facing the blind, was proposed by Lindsay and Littlefair [66], but not implemented.

Window opening and closing behaviors have been monitored by similar photographic approaches as for window blinds, using contact sensors, and by survey [19, 27, 67]. The position of hinged windows (e.g., casement and awning windows) is more difficult to visually assess because angular adjustment translates to only small apparent movements if the camera is aimed perpendicularly to the façade. The majority of the literature has focused on window openings as a binary state; thus there is less knowledge on how occupants adjust partially open or close windows. This is likely because researchers have predominantly used contact sensors which cannot distinguish position when a window is open [68]. Door opening as an adaptive comfort measure has been seldom studied and is primarily relevant for naturally ventilated buildings to enhance cross-ventilation. Haldi and Robinson [19] and Ooka and Komamura [69] found door position to be relatively independent of indoor and outdoor temperature. Similar monitoring methods can be used for door and window openings alike.

Thermostat adjustments are best measured directly through integrated sensors or setpoint logs [70-72], as air temperature alone is influenced by many factors (e.g., solar gains and window openings). Modern digital thermostats may provide logging capabilities and the resulting data is often available remotely via the internet - especially for web-enabled thermostats. The majority of research on thermostat is survey based [73]. The results of surveys may help establish a modeling framework, though they do not provide the resolution of data required for building detailed statistical models.

Fan use is a dominant method for cooling in many buildings, particularly those which are warm but where air conditioning is a luxury. It has been studied by several researchers using surveys $[19,74]$. Fan use could further be monitored by plug-level meter and could possibly be determined by disaggregating electrical loads [75].

Clothing level does not directly impact energy use, but affects occupant comfort, which in turn influences occupants' other adaptive behaviors. Such sequences of actions are discussed in Section 4. Clothing level, cannot be practically sensed electronically in-situ; therefore observations and surveys have been used [19, 41, 76]. Even observations are not ideal because researchers cannot ascertain undergarments without asking occupants. Clearly, occupants may feel uncomfortable in accurately reporting their undergarments or lack thereof. A further gap in the literature is understanding of small midday clothing level adjustments $[77,78]$ and clothing levels in homes.

Weather data is typically an input for most models dealing with occupant interaction with facades and clothing. The literature indicates that data sources include local weather stations (e.g., at airport), weather stations on the subject building, and even using spot measurements or descriptors (e.g., cloudy). Ideally, 
weather should be obtained from an on-site weather station due to spatial differences from local weather stations [79]. Furthermore, if solar radiation on the façade is desirable, it should be measured using a pyrometer mounted on the façade. Sky models may lead to error - particularly for partially-cloudy skies. Rain and wind speed/direction, which also vary spatially, are ideally measured on-site if they are to be used as model inputs.

Indoor temperature and relative humidity $(\mathrm{RH})$ are important parameters for predicting window and door opening, thermostat adjustments, and clothing levels. Similarly, indoor air quality (IAQ) has been found to be a probable factor for window opening actions [80-82]. These quantities can be measured using deployed sensors; but care must be taken to place them away from heat, moisture, and contaminant sources (equipment, people, and solar radiation) so that their readings are representative. Given that most zone modeling approaches and tools (e.g., in EnergyPlus and ESP-r) used for research and design assume that air is fully-mixed, model development based on sensor networks with high spatial resolutions may offer limited benefit over single-sensor configurations. Thus, positioning a single set of sensors such that they detect representative temperature and relative humidity is critical. To a similar extent, most building simulation models used in practice do not spatially discretize air velocity; thus detailed long-term measurements at more than one location would be of limited practical value. Spaces with displacement ventilation, radiant heating or cooling and large exterior surfaces may justify a higher spatial resolution of sensors.

The dominant monitored daylight-related quantity to predict light and blind use is workplane illuminance, though some researchers have used transmitted insolation, exterior insolation, and exterior illuminance [47]. Measurement of daylight with interior sensors is highly-preferable because this greatly reduces the extensibility of results by reducing the effect of window geometry and type. Workplane illuminance has historical precedence as the main metric for lighting design [83]; though it is unclear whether it is suitable since work in modern spaces is often performed on vertical surfaces (i.e., computer monitors) [65, 84]. Further practical challenges arise because there is a risk that occupants will cover or shade sensors on the workplane. Nevertheless, workplane illuminance is a good indicator of light and daylight availability and has been shown to be a relatively good predictor of light and blind control [34]. However, luminous intensity and the direction of its source are better indicators of daylight glare [85]. Numerous daylight glare metrics have been developed based on laboratory experiments, though they mostly require occupant position and orientation as an input - making them difficult to apply to models [86]. Measurement of glare using a high dynamic range (HDR) camera has been focused on short-term studies [e.g., 87] and further research is needed to demonstrate whether this method would be worth the additional cost, effort, and complexity.

There is little quantitative research on noise on occupants' window and door-closing behaviors, though it should be monitored in the future using indoor sensors. Occupants are frequently faced with making compromises between leaving windows open for better thermal comfort and indoor air quality and keeping them closed to prevent excessive noise transmission.

\subsection{Occupant surveys and interviews}

The value of occupant surveys and interviews is not immediately apparent upon the availability of a rich dataset obtained from sensors. Early research on occupant behavior used surveys to develop a greater understanding of the predominant behavioral characteristics or motivating factors for interacting with building systems $[82,88,89]$. 
Despite the revealing nature of surveys and interviews, there are some fundamental issues including: 1 ) participants knowingly or unknowingly misrepresent their behavior [90], 2) participants may not recall their behaviors and the severity of discomfort [91], and 3) participants may respond the way they think they are expected to. These issues could be partially resolved by using frequent computer-based surveys in which occupants are frequently prompted to report their comfort and/or behavior in recent history [e.g., 19]. Further research is required to validate that reported actions were actually taken and that the presence of the survey did not affect behavior. Furthermore, surveys should be developed using established methodologies and the complete survey should be published with the results.

\subsection{Laboratory studies}

Controlled laboratory-based studies in the field of occupant behavior modeling plays an important role in assessing occupant comfort conditions and establishing measurements. For instance, this method was used to develop the Fanger thermal comfort model and Daylight Glare Probability (DGP) [85, 92, 93]. Laboratory studies can also be used to understand physiological response to environmental stimuli and study the relative effect of age, culture, gender, etc. However, it is unclear whether behavioral models can be developed from laboratory settings due to the lack of longevity and natural working or living environment. For instance, many behaviors have been observed to be infrequent - on the order of days or months [e.g., 14]. It could be impractical to perform laboratory studies over this period while studying an adequate number of occupants. Other challenges include generalizability of laboratory-based behavior studies include the difficulty in reproducing a realistic environment regarding: social constraints and dynamics, lack of stressors, and unfamiliarity with the environment and available adaptive behaviors. Numerous other limitations to studying human behavior in a laboratory setting have been established by the literature [94, 95].

\subsection{Unresolved issues in occupant monitoring}

\subsubsection{Reporting contextual factors}

The differences in building design, culture, and climate put the universality of occupant behavior monitoring and modeling studies in question. For instance, window opening behavior in a naturally ventilated building would normally be very different than in an air-conditioned building. Similarly, government office buildings may operate on a different schedule than a law firm. Contextual factors are often reported by researchers along with the measured quantities of interest, though their role is often underestimated [96]. A standardized procedure for reporting contextual factors is needed so that potential users of datasets and models can judge the applicability to the building of interest. As for model inputs, identifying insignificant contextual factors can greatly reduce data collection efforts.

\subsubsection{Sampling: how long, how frequent, and how many people?}

Monitoring studies have ranged from a day to multiple years [e.g., 34, 62]. The seasonal effect of many occupant behaviors and occupancy could require a full year of monitoring. Furthermore, longer term behavioral effects (e.g., habituation and acclimatization [97]) have been reported and may necessitate continuous monitoring that lasts at least a season and ideally a year. More research is required to determine whether multi-year studies are worthwhile exercises.

Sampling frequencies range from minutes to several times per day; some studies use event-based sampling (e.g., time of a light activation). Many developed occupant behavior models use a five minute timestep [25]. Most behaviors are relatively infrequent (e.g., at most several times per day for lights, blinds, and windows and on the order of ten times per day for arrival and departure [45]); thus, sampling periods of 15 
minutes to 1 hour are generally suitable and any errors are likely to cancel out over a whole-year simulation. Existing occupant monitoring studies typically range from ten to several thousand occupants [47]. Diversity between occupants' behavior is significant (e.g., Figure 5), thus an adequate sample to represent the population is required $[14,98]$.

Age, gender, race, and cultural differences between occupants' comfort and behavior have been established [82, 99-101]; thus, researchers should take care to report these traits for the sake of those who apply the resulting model. Ultimately, sample size should be chosen such that minimal additional information is obtained by adding another participant. Established methods for determining adequate sample size, such as power analysis, are available in the literature [102].

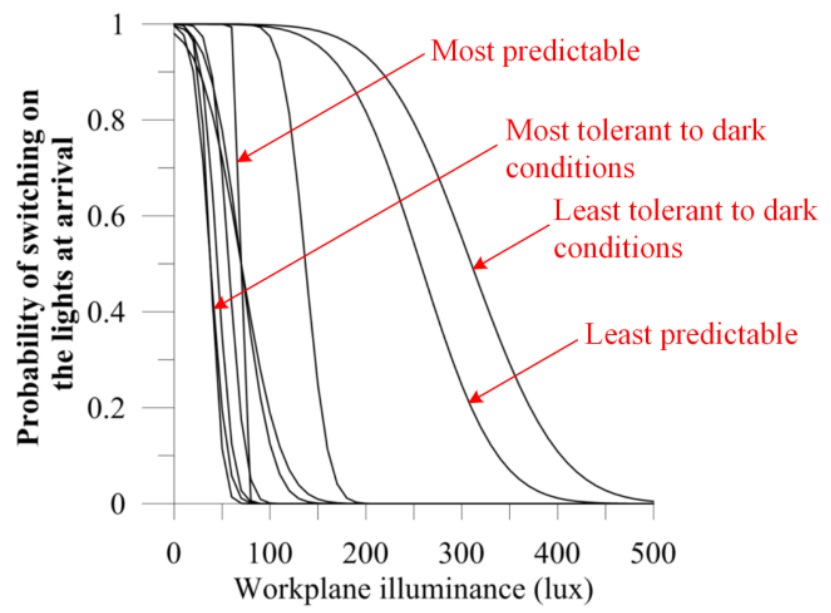

Figure 5: Example of occupant diversity: each line represents a logistic regression for the probability of an individual office occupant to turn on their lights upon arrival (modified from [33]).

\subsection{Summary}

In summary, behaviors of interest are categorized as occupancy and plug loads and discomfort-driven adaptive behaviors. The former category can be studied using various occupancy detection and counting technologies and electrical power meters, though cost, privacy, and accuracy remain challenges. Monitoring adaptive behaviors requires measurement and logging of both the behaviors themselves and the significant predictive environmental variables.

Ideally, occupants would not be aware that they are being monitored, since they may change their behavior once they know they are being observed [103]. There are, however, organizational, legal, practical, and ethical limits on the extent to which this can be achieved. Detailed guidelines on all discussed aspects of occupant monitoring will be written as part of IEA EBC Annex 66.

\section{Model development}

Occupant behavior models, in the current context, are developed to equip designers with the tools to better predict the energy performance of buildings. To ensure that models are applicable in design, they should be capable of accurately predicting occupants' energy-related behavior in buildings other than those from which the data have been obtained. This requires models to capture major properties in the behavior of occupants, (e.g., randomness, diversity among individuals and complexity in factors aforementioned), without the peculiarities that the source data could introduce. For the widespread use, occupant models 
should be practical, robust, and have a manageable number of inputs that are readily available in BPS (or the subcategory building energy modeling (BEM)) tools. This section reviews major occupant behavior modeling aspects.

These sections are summarized from common experiences in modeling occupant behavior. The problem a model tries to deal with should first be identified before building it. This topic is discussed in Section 4.1. During modeling, several assumptions would be introduced, while independent variable and model formulations are selected. Although numerous models have been built, it is necessary to look back as well as think over whether some questionable points exist in this modeling procedure. These are discussed in Section 4.2, which is divided into parts dealing with the assumptions, driving factors, and formulations. After that, we discuss the combination of multiple inputs, behaviors and occupants, as well as the representation of occupant diversity in Section 4.3 to 4.5 , which are rarely addressed in current occupant behavior modeling and need further efforts.

\subsection{Levels of modeling}

The ultimate goal of occupant modeling is to serve the building design and operator community and requires models to balance practicality with accuracy. It is accepted that not every single contributing factor to occupant behavior can be captured but that models can be developed to provide a reasonable prediction of occupants in most situations. In early design stages, the knowledge of the typical range of occupant behaviors can be useful. For instance, if the designer is targeting a specific energy use level for a large building, an occupant's stochastic nature maybe concealed by the statistical effect of aggregating numerous offices. Thus, a simple whole-building lighting schedule may suffice to describe the lighting use properly, instead of developing and applying an agent-based stochastic model for each occupant [104]. However, when the focus is on a single office where the lighting is used in a random way, a stochastic model may be more realistic than a pre-determined schedule.

As Melfi, et al. [105] stated, there are three major dimensions of model resolution, (1) temporal, (2) spatial, and (3) occupancy (see Figure 6). Temporal resolution refers to the precision in which the timing of events is modeled. Spatial resolution refers to the precision of physical scale (e.g., whether the model predicts number of people in a building or zone). And finally, occupancy resolution refers to how the model specifies people. This includes models or sensors that may only specify whether at least one occupant is present, while others may be capable of specifying the specific activity that the occupant is engaged in.

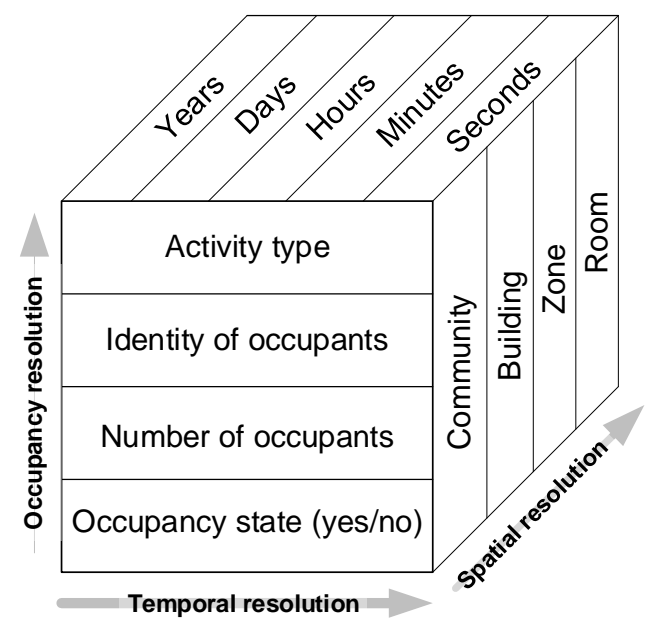

Figure 6: An illustration of different temporal, spatial, and state resolutions for occupancy modeling (modified from Melfi, et al. [105]) 
The appropriate model resolution depends on the problem that is being addressed. Before developing a model to describe occupant behavior, it is necessary to clarify the resolution for each dimension: spatial, temporal, and occupant resolution. A single model is unlikely to be generic enough to cover all solutions at different scales. For occupant models to address various scales (room, building, community) and design stages, an array of models needs to be developed.

\subsection{Technical aspects in modeling}

\subsubsection{Assumptions of modeling}

Normally several assumptions are introduced during occupant behavior modeling to simplify model development while maintaining the applicability of the model. However, some assumptions must be carefully discussed. For example, in current occupant behavior simulation, there is an underlying assumption that occupants take actions that are dependent only on their previous state (i.e., they are modeled as being memoryless) [27]. If the environment remains unchanged, the probability for an occupant to take an action is fixed. However, the assumption of being memoryless is not rigorously discussed or validated. It is possible that occupants behave with a previous memory of discomfort and environment. In this case, the probability varies even under the same environmental condition. Those who are less tolerant to an uncomfortable condition are more likely to take actions the longer they stay. Those who are more tolerant to an uncomfortable condition tend to maintain the same state, feeling uncomfortable.

\subsubsection{Determination of driving factors}

As discussed in the previous section, normally one or more parameters (e.g., indoor air temperature or time of day) are the driving factors of occupant behavior in a behavioral model $[30,68,106]$. However, a correlation between the two does not necessarily mean that the input parameters are the driving factors of behavior. A model that uses excessive inputs or is excessively complex is known as an over-fitted model. However, the inputs may influence the behavior in some indirect and unexpected way. For example, an occupant opens the window when the indoor temperature is high, which, in turn, is strongly influenced by the profile of outdoor temperature. If the outdoor temperature is used as a direct input of the model regarding window operation of occupants, it may actually not be applicable in another scenario with a different building envelope.

To develop a robust behavioral model, a logical explanation for the cause and effect of behaviors should be sought to complement the statistical model alone. For instance, as previously mentioned, considerable insight about occupant behavior can be gained through interviews and surveys with open-ended questions. Without the knowledge about the perceptions or actions of occupants, the cause and effect can be mistakenly interpreted.

\subsubsection{Model formulations}

There are three major forms of stochastic occupant behavior models that are in common use: Bernoulli process, discrete-time Markov chain, and survival analysis. Figure 7 shows sample graphs from the literature for each of the three forms.

1. Bernoulli process. Bernoulli processes, are perhaps the most simplistic of stochastic models in that that the probability of an event or state is not dependent on the previous state (i.e., memoryless). The advantage of the Bernoulli processes is that the scope can be efficiently applied to the wholebuilding level (e.g., the fraction of lights are on or occupants are in their homes). This is useful for 
energy modeling at the large scale, but does not describe individual comfort/behavior and it does not predict the timing of individual behaviors. As previously mentioned, in early design such an approach may be useful since Bernoulli processes are computationally efficient and do not require as much information.

2. Discrete-time Markov chain. Markov chains, in contrast to Bernoulli processes, depend on the previous state to predict the probability of an event occurring. This is useful for representing individuals' actions and the motivations for those actions. However, Markov chain models cannot be applied to populations of occupants, and thus computational effort scales linearly with the number of occupants modeled. An extension of Markovian models uses agent-based modeling for which modeled occupants can have a longer memory. These models specify how occupants interact with one another and with their environment [107-109]. An agent's specification includes their attributes, behavioral rules, memory, resources, decision-making sophistication, and any rules for modifying current behavioral rules. A wide range of human agent models are now available in the literature, including zero-intelligence agents, agents subject to reinforcement- or belief-based learning, and agents that can evolve new behaviors and modes of learning and behavior [110]. To characterize the behaviors of building occupants, one appropriate agent modeling framework is the Belief-Desire-Intention (BDI) model [111]. BDI models seek to mimic the practical reasoning processes by which humans make "right" decisions, given the structure of their personal values and society's norms. Agents in these models are "rational and have certain mental attitudes of belief, desire, and intention, representing, respectively, the informational, motivational, and deliberative states of the agent" [112].

3. Survival analysis. Survival analysis was originally used to predict the probability of how long somebody will live. In general, survival analysis is used to estimate the time duration until an event occurs. The same method can be applied to occupant behavior models. For instance, survival models can estimate how long a building is likely to remain unchanged by occupants. Unlike the previous approaches, survival analysis is a continuous time approach, meaning that they may specify some period of elapsed time before an action is taken.
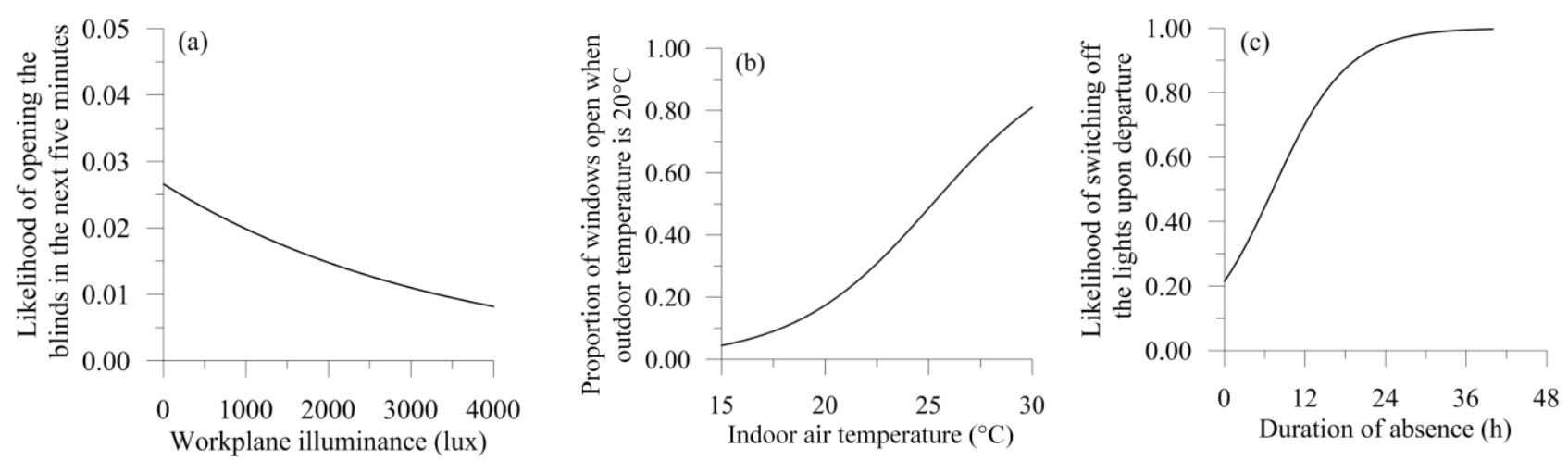

Figure 7: Representative models illustrating (a) a discrete-time Markov model [34], (b) a Bernoulli model [19], and (c) a survival model [33].

The above modeling approaches generally lend themselves well to current BPS algorithms, with fixed and known time steps. Another promising approach is the discrete event formulation, which is triggered not at each time step but when a significant change in the values of model inputs changes. Gunay, et al. [113] showed that discrete event formalisms can yield greater flexibility for occupant behavior modeling because the models are not constrained to being used with a specific time step frequency. 
For model development, the form of the equation should fit the data as well as possible while considering practical constraints. Furthermore, a proper probabilistic model must not contain physical impossibilities (e.g., probabilities greater than 1 or less than 0 ) for the possible parameter ranges. The mathematical form of the equation is usually pre-determined or decided by evaluating the fit for various generic formulations. Logistic regression models (e.g., Figure 5) are the dominant form of models used to represent the probability of the occurrence of operations related to input parameters. There are nevertheless, other forms like quadratic, sigmoid function [114], and probit [74].

\subsection{Incorporation of qualitative model inputs}

A number of researchers $[34,115]$ have studied occupant behavior by monitoring numerous measured quantities in order to isolate those which are the best predictors of an event or state. The procedure used is to determine which inputs are the best predictors and to only include those which provide a significant improvement in the predictability of the behavior. The degree to which the model should fit the data is subjective and depends on the intended application.

As previously mentioned, occupants behave in a stochastic way influenced by multiple factors - many of which are immeasurable and unanticipated. For instance, a survey conducted on the air-conditioning and window operation in residential buildings by Li et al. [7] revealed that occupants may open a window if they feel hot in the summer, and also if they feel stuffy. Thus window operation could be related to both indoor temperature and air quality. Besides these environmental factors, window operation may also be influenced by living habits, following a more deterministic schedule. For example, the study participants sometimes opened the window when waking up in consideration of getting fresh air from outside, regardless of the perception of indoor air quality. The non-environmental (i.e., contextual) factors are not explicitly included in models because they typically focus on the relationship between behavior and environmental factors. However, these factors can be as significant as the environmental ones.

There are two methods to describe the behavior influenced by multiple contextual factors. The first is to combine all the parameters together in one equation. The latter is to treat the factors to influence behavior independently, thus they could be separated in different formulae. For example, Haldi and Robinson [34] developed model coefficients for both blind control upon arrival in an office and during the work day. This approach can introduce non-environmental, discrete and/or non-quantitative factors.

\subsection{Modeling sequence of behaviors}

Until now, only single behavior models have been discussed. But normally, occupants have a wide array of adaptive opportunities and other energy-relevant behaviors. Often two behaviors can achieve the same goal (e.g., removing an article of clothing or turning on a fan both help to cool an occupant), though at different levels of effectiveness, effort, and energy intensiveness. There could also be situations where two actions are needed (e.g., open office door and window to provide cross ventilation) or interfere with each other (e.g., closed blinds reduce airflow through an open window). When multiple behaviors are considered, an additional model layer needs to address how to combine different behaviors together. Such modeling is rare in the literature [116], but essential to the practical application where occupants may choose various ways to adjust their indoor environment. This layer is like a negotiation among different behaviors to decide what action is simulated to be taken when multiple behaviors could be triggered under certain circumstances. The dataset required to consider the sequence of multiple behaviors is substantially greater, since observations of how the actions are taken with respect to each other are required. That is, sufficient data needs to be collected such that the model can predict that a given action will be taken, provided that some other actions have already been taken and the environmental conditions. Furthermore, 
the applicability of these multi-behavior models is less clear, since they are only valid if the occupants in the simulated building have access to the same set of behavioral opportunities.

\subsection{Inter-occupant diversity and modeling multi-occupant spaces}

Occupant behavior modeling in the literature mostly treats all occupants as a whole, making no discrimination in the data collected in each room and of each occupant. Since data is often merged, the distinction among occupants is lost. With this, only an "average occupant" can be modeled, which is more representative of a statistical concept than a real occupant. It should be noted that occupants behave quite differently even under identical conditions, but also that there are known effects of occupant age and sex [99]. Only if occupants are studied individually will the developed model be able to reflect the diversity of occupants [98].

Two schools of thought have emerged with regards to modeling occupant diversity: classifications (e.g., passive and active) $[33,63,117,118]$ and a continuous distribution [98]. Both approaches have their merits, although there is little evidence that all occupants can be perfectly categorized. A continuous distribution of occupant traits offers greater flexibility. However, having one or a small number of typical occupants may gain greater industry appeal as it is conceptually simpler and does not require as many simulations.

The interaction of multiple occupants in a space may alter the patterns of behavior of each occupant. It is not simply a composition of behavior probabilities of each individual; the presence of other occupants impacts an occupant's behavior in complex psychological and social ways [96]. This plays a substantial role in shared office spaces. For example, Haldi and Robinson [34] reported that occupants in private office spaces tend to undertake blinds control actions more frequently and at lower workplane light intensity levels than occupants in shared office spaces. When possible, the influence of such latent factors should be quantified and incorporated in the occupant behavior models. To address the problems related to multiple occupants assembling, an additional layer of modeling may be introduced. This additional negotiation model decides whether operation actually occurs according to the individual occupant (attached with identical or distinct models and parameters), and also the interaction among them. In this way, when it comes to real case simulation, each occupant should be modeled and followed by the negotiation layer model dealing with interactions. This can be achieved using agent-based modeling, as previously described.

\section{Model evaluation and application}

\subsection{Introductory remarks}

Thus far, we have argued that people's presence, activities, and actions exert a considerable influence on the performance of buildings in view of energy use and indoor climate. Moreover, it is evident that buildings' performance cannot be properly appraised without due consideration of occupant-related variables. Building performance simulation applications thus typically include some representation of occupants' presence and activities in buildings. Such representations or models can be very different, both in terms of the underlying theoretical underpinnings and with regard to resolution. As discussed in Section 4, the modeling approach, whether it is a black-box, data-driven model or a model with explicit law-like causal relationships, should be carefully selected and adopted. Furthermore, model evaluation cannot be conducted without considering the model's intended application. For instance, researchers should ask themselves: Are assessments conducted to benchmark a specific design solution against applicable standards? Are assessments meant to compare the performance of alternative design solutions? Or do they 
mean to reveal the uncertainty implications of people's control actions for the values of building performance indicators?

Independent of their inherent structure and resolution, occupancy models deployment in the building assessment process requires that they undergo a proper evaluation process. Note that we consciously do not allude to the phraseology of "model validation". Given the current state of affairs in this field, it is advisable to be careful with the use of terms such as "validation" and what they imply in a properly understood scientific context.

Before directly addressing the model evaluation challenge, a brief discussion of some basic considerations is provided. As with many other modeling areas, the reliability of building performance simulation results not only depends on the validity of computational algorithms, but also on the soundness of input assumptions. As previously discussed, two fundamental issues must be considered with regard to the reliability of occupancy-related models: 1) model resolution should match the context in which the model is applied; 2) qualitative building and occupant traits pertaining to cultural background and working styles need to be incorporated. For the latter point, large data sets may be required to properly assess these factors' effect and properly develop a rich set of models that could cover typical application scenarios.

\subsection{Data availability and quality issues regarding occupancy}

As noted earlier, there is a substantial and growing body of observational studies regarding occupants' presence in buildings and their interactions with buildings' environmental control systems such as windows, shading elements, and luminaires $[33,36,38,62,68,74,119,120]$. Observational data provide the basis for descriptive or stochastic methods that can be incorporated in building performance simulation applications. Existing studies in this area do however display various limitations, due - amongst other things - to the small number of buildings involved, the duration, consistency, and accuracy of data collection, the robustness of the analyses, and the clarity of the documentations. Such limitations limit the application scope of the proposed models.

The pattern of occupants' presence in buildings is typically the starting point for model development. However, it cannot be simply inferred from building type and function (e.g. residential versus commercial). Nor can it be derived solely based on organizational information obtained from facility managers. For instance, in a large-scale study of office buildings in Austria, the occupancy patterns were quite diverse and unlike either conventional assumptions in building performance simulation practices or presumptions of those in charge of the buildings' management [2]. Mixed use buildings with both residential and commercial spaces pose a further challenge. But even if all spaces in a building are used by a single organizational entity, they could still differ considerably with regard to their occupancy patterns [2]. As artefacts with very long life spans, buildings have to accommodate continuously changing user groups and entities, which implies again variable and hardly predictable occupancy patterns. Moreover, offices can be, in the course of time, assigned to different individuals (or user groups) with inherently different working habits and schedules. Even the same individual occupant might, over time, display varying patterns of presence because of changes in their professional or personal circumstances. To highlight the relevance of these observations in the context of building performance simulation, let us consider tool applications in scenarios involving both building design and building operation:

- To conduct performance simulations toward design decision support, occupancy input assumptions could use one or a combination of: (i) standardized profiles; (ii) data provided by the client (e.g. 
building owner or tenant); (iii) available empirical data regarding the relevant building type and function. All these resources involve considerable - and possibly indelible - uncertainties.

- Occupancy-related information intended as input for simulation models used in a specific existing building (e.g. for applications in facility management or building automation) can yield higher reliability if it is based on systemic monitored data in that building. However, a substantial residual uncertainty might be unavoidable even in this scenario.

\subsection{Challenges of occupancy action models}

Models of occupants' active control-oriented interventions in buildings face additional challenges. Using observational data, it is possible to reveal statistically significant relationships between the frequency or probability of user control actions (operation of luminaires, blinds, windows, etc.) and one or more independent variables regarding indoor climate or outdoor conditions. These kinds of empirically based correlations are sometimes referred to, erroneously, as deterministic. In fact, they are simply observationbased statistically aggregated functions [2]. They can ideally incorporate knowledge of the environmental triggers of building occupants' behavioral tendencies. However, they certainly do not represent causal models of human control actions in buildings. Furthermore, similar to other statistically obtained functions, these kinds of models are at least two limitations:

First, they cannot be uncritically divorced from their underlying population and simply applied to other circumstances without losing much of their statistical credence: A multitude of factors (climate, cultural context, building typology, accommodate functions, specific organizational attributes, building systems peculiarities, spatial configuration, layout, and orientation, interior design features, etc.) influence user behavior and its dependence on suspected independent variables. Second, aggregate models do not explicitly reflect the probabilistic and highly dynamic nature of control-oriented control use actions, as the stochastic user action models can - at least in principle [74, 121, 122].

The latter models have been used to generate time series of both occupancy intervals and user control actions that can be highly similar to actual processes. If grounded in sufficient and adequate empirical data, probabilistic occupancy and control action models could properly represent the tendencies and patterns of occupancy-dependent processes in buildings. Such models can be implemented in simulation applications for example in terms of autonomous agents with embedded rules and methods [123-125] to generate realistic behavioral data. However, the promise of probabilistic models of occupancy-related phenomena in buildings must be qualified against both reliability and applicability criteria.

\subsection{Generation of realistic action patterns and predictive performance}

Note that the potential of stochastic models to generate realistic patterns of presence and action does not automatically translate into a high level of predictive performance. We need to underline this observation, given the persistence of some related misconceptions. If properly calibrated based on relevant empirical data, a stochastic model may realistically emulate the general patterns of occupancy-related processes and events in a building with stable functional and organizational assignments. But this does not necessarily establish its scalability toward anticipation of long-term future processes and events (predictive potency) or toward transportability to other buildings and other locations. Given the recent surge of proposed probabilistic behavioral models, we may be going through the "inflated expectations peak" phase of the socalled "hype cycle" [126]. Claims to the probabilistic model's inherent predictive superiority appear to be rather premature: Emulation of occupancy-related patterns that look similar to real observations should not be confounded with actual predictions of future states and events in specific spaces of specific 
buildings. Such misconceptions can be disposed of if one seriously reflects on the complexity of human behavior, especially in socially relevant circumstances (see, for example, Watts [127]). More specifically, researchers in this field must assiduously upheld the appropriate scientific standards for model "validation". These include, amongst other things, careful collection and preparation of sufficient and representative empirical data, systematic separation of underlying data sets for a) model generation and b) model evaluation, and candid discussion of the proposed model's limitations in view of statistical significance and applicability. Toward this end, double-blind studies (involving where the tasks of data collection, model development, and comparison of empirical and computational results are conducted by separate agents) or round-robin tests would be most convincing. Note that in many research areas (e.g., medicine, epidemiology, psychology), double-blind experiments are conducted as a matter of course [see, e.g., 128, 129]. So far probabilistic models of occupancy and user control actions have not been subjected to such rigorous tests. Until relevant scientific criteria are consistently met in the respective model "validation" studies, scepticism would be the proper attitude toward any claims pertaining to the models' predictive performance.

\subsection{A note on model applicability issues}

Aside from validity concerns, which all kinds of occupancy-related models must address, we must also deal with model applicability questions. An argument can be made in favour of simple (code-based or descriptive) occupancy-related models in the design development phase, of when simulation is deployed to obtain the values of aggregate performance indicators such as buildings' annual heating and cooling loads. Using aggregate performance indicators, one can presumably benchmark a specific building design proposal against applicable codes and standards. Likewise, such aggregate indicators can be used to compare the likely performance of multiple design alternatives, which can differ in view of variables pertaining to the building's envelope, massing, orientation, shape, construction, etc. Thereby, the comparison is conducted under the arguably cogent assumptions of "standardized" conditions pertaining to external climate (typically represented in terms of reference weather files) and internal occupancy-related processes (conventionally represented in terms of reference profiles pertaining to internal gains, ventilation rates, etc.).

However, a different circumstance arises, if more involved use scenarios are considered in which the uncertainties associated with occupancy-related processes in buildings are inherently relevant to (and can have critical implications for) the outcome of the simulation-based queries. Consider the following example: As it was alluded to before, differences in occupancy patterns over time and location can be quite significant. Such differences can be important especially while trying to gauge the variance of thermal loads or conditions in various zones of a building. Information regarding temporal and zonal load variations is critical, for example, when essential data for design and sizing of HVAC systems is to result from simulation studies. Thus, simple models of user presence and behavior that ignore their probabilistic fluctuations (and the resulting uncertainties) would be rather problematic, if the detailed sizing and configuration of the mechanical equipment for a building (or for a specific zone of a building) is the main concern query: The efficient provision of sufficient heating and cooling capacity to different zones of a building necessitates that the variability of required thermal loads be systematically explored. In such instances, the deployment of properly calibrated probabilistic models can be advantageous.

\subsection{Toward a sound model evaluation process}

Given the preceding treatment, the following set of requirements with regard to the evaluation of occupancy and action models emerge: 
Properly collected, structured, and interpreted observational data is sine qua non for subsequent occupancy and action model development and evaluation processes. Aside from the standard technical requirements (sensory infrastructure, data quality, sample size and sampling frequency, etc.) and statistical treatment quality, psychological and social considerations (such as those pertaining to the Hawthorne effect) need to be explicitly addressed.

The nature (causal, data-driven, etc.) and the spatial and temporal resolution of the models that are to be evaluated must be clearly defined and explicitly stated. Likewise, the intended application has to be specified (building design, code compliance, building systems sizing, building control processes, etc.) as it has concrete implications for the logic of the evaluation procedure.

The objectives of the evaluation process must be unmistakably specified. For what specific aspect of the model performance is the evaluation process supposed to provide evidence? Is the objective to display the model's capability of merely reproducing general tendencies or rather exact (spatio-temporal) replication of observational data? Is the objective to provide evidence that the model has specific predictive potency? What specific statistical indicators are used to measure and express the model's performance?

The standard scientific criteria and procedures in model evaluation activity must be considered and abided by. Adequate reasoning must be provided as to the reasons for deviations from such due procedures. Instances of relevant practices include, for example, the separation of data sets for model development and model evaluation, selection of a "double-blind" design for the model evaluation process (with distinct model developer and model evaluator roles), execution of "round-robin" test for the comparative measurement of the performance of alternative occupancy models. Researchers in the building performance simulation domain in general and those involved in the building occupancy modeling in particular have a professional obligation to apply the highest possible standards of scientific inquiry in conducting observations, developing models, and performing evaluation studies. This is a precondition for sustained intellectual progress and sound practical application in the field.

\section{Integration of occupant behavior models with building energy modeling programs}

Integration of occupant behavior models with existing building energy modeling (BEM) programs enables researchers, and more importantly, practitioners to simulate energy-related occupant behaviors in buildings and their impacts on energy and environmental performance of buildings during the building design, operation, and retrofit process to reduce energy use and improve indoor environment.

\subsection{Simulation Approaches}

Four main approaches have been used to include occupant behavior in building simulation using current BPS programs.

\section{1) User defined profiles and rules}

Almost all BPS programs allow users to define and input temporal schedules of thermostat settings (cooling and heating temperature setpoints), occupants, lighting use, plug-loads, and HVAC system operations. User defined profiles also include specified deterministic rules governing operation of building components and systems. For example, shading devices will be deployed if a space has too much solar heat gains causing thermal discomfort or problem of glare causing visual discomfort; windows will be open if the indoor 
temperature is high and outdoor temperature is lower than the indoor temperature; electrical lighting will be dimmed or completely turned off if a space has some or adequate daylight to meet occupant visual comfort needs. This approach is straightforward and easy to use, but limited in terms of flexibility - users cannot create new categories of profiles beyond what can be accepted by a BPS program, and users cannot create new categories of rules. Another limitation is the user defined profiles and rules are deterministic and simplified without fully considering the stochastic nature and complexity of occupant behavior in buildings.

\section{2) User customized code}

The second approach is that the user can write custom code to implement new or overwrite existing or default building operation and supervisory controls. For example EnergyPlus has the Energy Management System feature and DOE-2 (LBNL) has the user function feature that implements such functionality. This approach provides flexibility by enabling users to change how a BPS program simulates a building energy model without having to recompile a BPS program. It also allows certain degree of stochastic modeling of occupant behavior by using built-in or user-defined stochastic mathematical functions. However this approach usually requires advanced user experience and deep knowledge of a particular BPS program in order to use such feature correctly and effectively. Another limitation is most BPS programs with such feature lack comprehensive debugging mechanism which hinders usability and the user-written code can only be called at certain predefined points within a BPS program; the user cannot create new calling points.

\section{3) User customized tools}

For open source BPS programs, users can implement occupant behavior models by adding new code and changing existing code in a BPS program, and recompile it. Theoretically this approach offers the most flexibility but requires professional computer programming experience and in-depth knowledge of a BPS program in order to implement this approach correctly. Another limitation is such recompiled programs are usually for private use and they may not go through robust testing and evaluation process to guarantee the quality of the programs. Finally, documentation about the modeling approach and limitations may not be provided to model users; thus risking inappropriate use of the model.

\section{4) Co-simulation}

Co-simulation is a simulation methodology that allows individual components to be simulated by different simulation tools running simultaneously and exchanging information in a collaborative manner [130]. It exploits the modular structure of coupled problems in all stages of the simulation process beginning with the separate model setup and preprocessing for the individual subsystems in different simulation tools (which can be powerful simulators as well as simple C programs). During time integration, the simulation is again performed independently for all subsystems restricting the data exchange between subsystems to discrete communication points. In this way, modules developed by different programming languages or in different physical computers can be executed in an integrated manner.

A limited number of advanced users [108, 109, 131, 132] started using the co-simulation approach integrating a separate software module of behavior models with EnergyPlus. The Building Controls Virtual Test Bed (BCVTB) [130] is a software tool that allows advanced users to couple different simulation programs for distributed simulation or for a real-time simulation that is connected to a building control system. BCVTB links user implementation of occupant behavior models either in MATLAB, Simulink, Modelica, Ptolemy or a user-custom program with EnergyPlus during run-time so they can exchange data 
as the simulation progresses. Besides BCVTB, EnergyPlus also supports the External Interface feature which allows EnergyPlus to co-simulate with occupant behavior software compiled as Functional Mockup Units (FMUs). The main limitations of co-simulation are primarily due to the limitations of Functional Mockup Interface (FMI) (e.g., supporting of dynamic arrays), handling of data exchange at different time steps, and computing run-time.

\subsection{Simulation Approaches adopted by BPS Programs}

For popular BPS programs used worldwide, EnergyPlus allows all four integration approaches; DeST [133] allows approaches 1 and 3 and it has an embedded behavior module; DOE-2 allows approaches 1 and 2; IDA-ICE allows approach 1 through 3; ESP-r allows approaches 1 and 3 and it has an embedded behavior module; and TRNSYS allows approaches 1 and 3.

The aforementioned behavior software modules can include occupant behavior models in various regression forms. For example, the deterministic user profiles or rules, and the stochastic models such as those based on the logit function which calculates the probability of an event according to a list of independent parameters. These models typically only account for inter-individual variability in behavior through the definition of "active" and "passive" occupant groups. They do not simulate multiple behaviors together or addresses behavioral sequencing. They do not account for social influences or other constraints on behavior in shared spaces $[96,109]$.

Although there are four existing approaches to integrating occupant behavior modeling with BPS programs, there are still significant challenges, as described below.

\subsection{Standard description of occupant behaviors}

Behavior models from different developers tend to be represented in diverse semantics. There lacks a standard framework to describe the models with adequate details that enable model exchange or reuse. The description of occupants in different models is not consistent, which makes it difficult to represent an occupant in a common format for programs to simulate. For instance, some papers provide graphs without model coefficients. Other papers gloss over details thus putting methodology and applicability into questions. Hong [134] started an effort developing a DNAs framework to describe energy related occupant behavior in buildings with four key components: (1) the Drivers behind energy-related occupant behavior, which are biological, societal, environmental, physical, and economical in nature, (2) the Needs of the occupants are based on satisfying criteria that are either physical (e.g. thermal, visual and acoustic comfort) or non-physical (e.g. entertainment, privacy, and social reward), (3) the Actions that building occupants perform when their needs are not fulfilled, and (4) the Systems with which an occupant can interact to satisfy their needs.

\subsection{Direct modeling of occupant behaviors}

Current BPS programs do not associate behaviors directly to humans in modeling and simulations. For example, in EnergyPlus, shading control rules are defined in the WindowProperty:ShadingControl objects rather than in the People objects. Similarly, window opening and closing rules are defined for window/fenestration objects. This can easily lead to disconnect of occupant behavior modeling involving multiple occupants or a series of related behavior actions.

\subsection{Flexibility and extensibility of the behavior software module}

As occupant behaviors are stochastic in nature, new data and research will produce new behavior models. The ideal behavior software module should be flexible and extensible to include these new behavior 
models with a minimal effort. The behavior module should build upon a standard framework which can capture behavior models describing various human activities at various temporal and spatial resolutions, and enables model exchange and reuse via the FMI co-simulation standard.

\subsection{Support of co-simulation in BPS Programs}

Most current BPS programs do not support co-simulation yet. Efforts are needed to enhance BPS programs to co-simulate with behavior software tools to fully capture the impacts of occupant behavior on building performance. There are challenges to address in the co-simulation, including the use of different time steps in a BPS program and the behavior tool (the majority of occupant behavior models are developed with a 5 minute time step [113]), the need for iterations between a BPS program and the behavior tool, as well as computational performance of the entire integrated simulation.

\section{Future perspective}

The current state and future challenges in occupant behavior modeling and simulation include data collection, modeling, evaluation of models, and integration with BPS programs. This section reveals the major research areas that need to be addressed or further addressed to advance the field of occupant behavior modeling and simulation.

\subsection{Data collection}

Data collection is often a costly process due to minimal standardization and the amount of equipment and time required. Arguments over the appropriate sample size for measurement duration frequency and the number of occupants exist. Furthermore, knowledge of the most suitable explanatory variables (e.g., air temperature) requires better data streamlining processes. Ultimately, the close communication between the data collection and modeling communities is required to ensure that a reasonable compromise between practicality and accuracy is achieved. Sensor development (e.g., small sensors that transmit data wirelessly and are self-powered), distributed sensor networks, and improvements to building automation systems shall greatly improve the potential for data collection. However, ethical considerations will remain as a debate in the community. There is a clear benefit to collecting data without the knowledge of the occupants (e.g., Hawthorne effect), however this becomes challenging while meeting privacy and ethical standards.

\subsection{Modeling}

Models to describe occupant behavior that are developed from measured data should still be viewed critically. Multiple levels of models should be developed to meet the demand of various levels of applications. The assumption that the discretization in the time step has no influence on the behavior of

occupants (e.g. which lies in the Markov and other probabilistic models) still remains to be discussed. There should be a reasonable and physical explanation when a parameter is considered instead of referring to the evaluation of data fitness alone. The mathematical form of occupant behavior models cannot be interpreted physically since the form is determined in an arbitrary way, with a lack of physical mechanism. Models should be able to capture some of the inherent nature of occupants to be applicable in common cases. The combination and interaction of multiple influencing factors, behaviors and occupants will fill the gap between academic research and simulation applications of occupant behavior, as occupants and environmental factors are usually strongly connected with each other. The variety of occupants is yet another equally challenging problem. A possible solution may be to conclude several kinds of "typical occupants" who discretely differ from each other. The typical occupant approach, which conceals the 
complexity of the underlying model, along with plain descriptions, is a probable path forward such that it serves industry.

\subsection{Evaluation of models}

The state of art in occupancy and action modeling with regard to model evaluation is not sufficiently developed. To establish a scientifically sound evaluation process, a high level of transparency and consistency is required for the entire process of model development and implementation. Occupancy and action models considered for an evaluation procedure need to be documented in detail with regard to the underlying empirical basis of the model and the deployed modeling technique. The model evaluation process should preferably use observational data not used in the model development process. Ideally, model evaluation should be conducted by an individual other than the model developer. Both the intended purpose of the developed model and the pertinent model performance criteria must be explicitly documented. The model evaluation report must explicitly document all model specifics and applicable limitations for the benefit of those implementing the models within simulation tools as well as those using such tools toward practical building performance evaluation applications.

\subsection{Integration with BPS programs}

A standard framework to describe and model occupant behavior in buildings needs to be developed to enable model exchange or reuse. A software module including typical occupant behavior models can be developed, built upon the standard framework. The goal of the software module is to allow use as a standalone feature, being called as DLLs and co-simulation via the FMI standard. Occupant behavior modeling is part of the broader occupant information modeling, which can be integrated with building information modeling to facilitate complete building and occupant data description and exchange. BPS programs need to fully implement the FMI standard for co-simulation with behavior modeling tools.

\section{Conclusion}

Researchers in the building performance simulation domain and specifically those involved with building occupant modeling have a professional obligation to apply the highest possible standards of scientific inquiry when conducting observations, developing models, and performing evaluation studies. This is a precondition for sustained intellectual progress and the development of sound practical applications in the field. This paper provided a comprehensive overview of the state-of-the-art and future research and industry needs with regards to occupant-related data collection and monitoring, modeling approaches, model evaluation, and finally model implementation into simulation tools. The IEA EBC Annex 66 aims to tackle some of these problems and challenges by providing insights into the design and operations of low energy buildings. Advancements require leveraging the expertise and resources of researchers and practitioners around the world to develop robust modeling of occupant behavior in buildings.

\section{Acknowledgment}

This position paper has benefited from broader discussion of occupant behavior in the International Energy Agency Energy in Buildings and Communities Program (IEA EBC) Annex 66: Definition and Simulation of Occupant Behavior in Buildings. This work was supported by the U.S. Department of Energy (Contract No. DE-AC02-05CH11231), and the China Ministry of Housing and Urban-Rural Development and the Ministry of Science \& Technology (Grant No. 2010DFA72740-02) under the U.S.-China Clean Energy Research Center 
for Building Energy Efficiency. The authors appreciate the technical editing effort of the article by Sarah C. Taylor-Lange of LBNL.

\section{References}

[1] International Energy Agency (IEA), "World: [Energy] Balances for 2012," ed, 2012.

[2] A. Mahdavi, "People in building performance simulation," in Building performance simulation for design and operation, J. Hensen and R. Lamberts, Eds., ed: Spon Press, 2012.

[3] W. Zhang, S. Tan, Y. Lei, and S. Wang, "Life cycle assessment of a single-family residential building in Canada: A case study," in Building Simulation, 2014, pp. 429-438.

[4] S. Attia, A. De Herde, E. Gratia, and J. L. Hensen, "Achieving informed decision-making for net zero energy buildings design using building performance simulation tools," in Building Simulation, 2013, pp. 3-21.

[5] P. Hoes, J. L. M. Hensen, M. G. L. C. Loomans, B. de Vries, and D. Bourgeois, "User behavior in whole building simulation," Energy and Buildings, vol. 41, pp. 295-302, 2009.

[6] C. Turner, M. Frankel, and U. G. B. Council, Energy performance of LEED for new construction buildings: New Buildings Institute Vancouver, WA, 2008.

[7] Z.-J. Li, Y. Jiang, and Q.-P. Wei, "Survey on Energy Consumption of Air Conditioning in Summer in a Residential Building in Beijing," Heating, Ventilation, and Air Conditioning, vol. 37, pp. 46-51, 2014.

[8] C. M. Clevenger and J. Haymaker, "The Impact of the Building Occupant on Energy Modeling Simulations," 2006.

[9] O. Guerra Santin, L. Itard, and H. Visscher, "The effect of occupancy and building characteristics on energy use for space and water heating in Dutch residential stock," Energy and Buildings, vol. 41, pp. 1223-1232, 2009.

[10] V. Fabi, T. Buso, R. K. Andersen, S. P. Corgnati, and B. W. Olesen, "Robustness of building design with respect to energy related occupant behaviour," in 13th Conference of International Building Performance Simulation Association, 2013, pp. 1999-2006.

[11] V. Belessiotis and E. Mathioulakis, "Analytical approach of thermosyphon solar domestic hot water system performance," Solar Energy, vol. 72, pp. 307-315, 2002.

[12] B. Lee, M. Trcka, and J. L. Hensen, "Building energy simulation and optimization: A case study of industrial halls with varying process loads and occupancy patterns," in Building Simulation, 2014, pp. 229-236.

[13] V. Fabi, R. V. Andersen, S. P. Corgnati, and B. W. Olesen, "A methodology for modelling energyrelated human behaviour: Application to window opening behaviour in residential buildings," in Building Simulation, 2013, pp. 415-427.

[14] C. F. Reinhart and K. Voss, "Monitoring manual control of electric lighting and blinds," Lighting Research \& Technology, vol. 35, pp. 243-260, 2003.

[15] A. D. Galasiu and J. A. Veitch, "Occupant preferences and satisfaction with the luminous environment and control systems in daylit offices: a literature review," Energy and Buildings, vol. 38, pp. 728-742, 2006.

[16] A. Al-Mumin, O. Khattab, and G. Sridhar, "Occupants' behavior and activity patterns influencing the energy consumption in the Kuwaiti residences," Energy and Buildings, vol. 35, pp. 549-559, 2003.

[17] G. Brager, G. Paliaga, and R. De Dear, "Operable windows, personal control and occupant comfort," ASHRAE Transactions, vol. 110, 2004.

[18] P. Warren and L. Parkins, "Window-opening behaviour in office buildings," Building services engineering research and technology, vol. 5, pp. 89-101, 1984.

[19] F. Haldi and D. Robinson, "On the behaviour and adaptation of office occupants," Building and environment, vol. 43, pp. 2163-2177, 2008.

[20] A. Roetzel, A. Tsangrassoulis, U. Dietrich, and S. Busching, "A review of occupant control on natural ventilation," Renewable and Sustainable Energy Reviews, vol. 14, pp. 1001-1013, 2010. 
[21] Y. Zhang and P. Barrett, "Factors influencing occupants' blind-control behaviour in a naturally ventilated office building," Building and environment, vol. 54, pp. 137-147, 2012.

[22] M. Foster and T. Oreszczyn, "Occupant control of passive systems: the use of Venetian blinds," Building and environment, vol. 36, pp. 149-155, 2001.

[23] S. D'Oca, V. Fabi, S. P. Corgnati, and R. K. Andersen, "Effect of thermostat and window opening occupant behavior models on energy use in homes," in Building Simulation, 2014, pp. 683-694.

[24] B. Dong and K. P. Lam, "A real-time model predictive control for building heating and cooling systems based on the occupancy behavior pattern detection and local weather forecasting," in Building Simulation, 2014, pp. 89-106.

[25] H. B. Gunay, W. O'Brien, and I. Beausoleil-Morrison, "A Critical review of state-of-the-art energy and comfort related occupant behavior in office buildings," Building and environment, vol. 70, pp. 31-47, 2013.

[26] H. B. Rijal, P. Tuohy, F. Nicol, M. A. Humphreys, A. Samuel, and J. Clarke, "Development of an adaptive window-opening algorithm to predict the thermal comfort, energy use and overheating in buildings," Journal of Building Performance Simulation, vol. 1, pp. 17-30, 2008.

[27] F. Haldi and D. Robinson, "Interactions with window openings by office occupants," Building and environment, vol. 44, pp. 2378-2395, 2009.

[28] G. Y. Yun and K. Steemers, "Time-dependent occupant behaviour models of window control in summer," Building and environment, vol. 43, pp. 1471-1482, 2008.

[29] Y. S. Lee and A. M. Malkawi, "Simulating multiple occupant behaviors in buildings: An agent-based modeling approach," Energy and Buildings, vol. 69, pp. 407-416, 2014.

[30] R. Andersen, V. Fabi, J. Toftum, S. P. Corgnati, and B. W. Olesen, "Window opening behaviour modelled from measurements in Danish dwellings," Building and environment, vol. 69, pp. 101-113, 2013.

[31] G. Y. Yun, P. Tuohy, and K. Steemers, "Thermal performance of a naturally ventilated building using a combined algorithm of probabilistic occupant behaviour and deterministic heat and mass balance models," Energy and Buildings, vol. 41, pp. 489-499, 2009.

[32] G. Newsham, "Manual control of window blinds and electric lighting: implications for comfort and energy consumption," Indoor and Built Environment, vol. 3, pp. 135-144, 1994.

[33] C. F. Reinhart, "Lightswitch-2002: a model for manual and automated control of electric lighting and blinds," Solar Energy, vol. 77, pp. 15-28, 2004.

[34] F. Haldi and D. Robinson, "Adaptive actions on shading devices in response to local visual stimuli," Journal of Building Performance Simulation, vol. 3, pp. 135-153, 2010.

[35] V. Inkarojrit, "Balancing comfort: occupants' control of window blinds in private offices," Citeseer, 2005.

[36] D. Hunt, "The use of artificial lighting in relation to daylight levels and occupancy," Building and environment, vol. 14, pp. 21-33, 1979.

[37] P. Boyce, J. Veitch, G. Newsham, C. Jones, J. Heerwagen, M. Myer, and C. Hunter, "Occupant use of switching and dimming controls in offices," Lighting Research and Technology, vol. 38, pp. 358-376, 2006.

[38] D. Lindelöf and N. Morel, "A field investigation of the intermediate light switching by users," Energy and Buildings, vol. 38, pp. 790-801, 2006.

[39] R. Yasue, H. Habara, A. Nakamichi, and Y. Shimoda, "MODELING THE OCCUPANT BEHAVIOR RELATING TO WINDOW AND AIR CONDITIONER OPERATION BASED ON SURVEY RESULTS."

[40] X. Ren, D. Yan, and C. Wang, "Air-conditioning usage conditional probability model for residential buildings," Building and environment, vol. 81, pp. 172-182, 2014.

[41] S. Schiavon and K. H. Lee, "Dynamic predictive clothing insulation models based on outdoor air and indoor operative temperatures," Building and environment, vol. 59, pp. 250-260, 2013.

[42] A. Mahdavi, A. Mohammadi, E. Kabir, and L. Lambeva, "Occupants' operation of lighting and shading systems in office buildings," Journal of Building Performance Simulation, vol. 1, pp. 57-65, 2008. 
[43] W.-k. Chang and T. Hong, "Statistical analysis and modeling of occupancy patterns in open-plan offices using measured lighting-switch data," in Building Simulation, 2013, pp. 23-32.

[44] J. Page, D. Robinson, N. Morel, and J.-L. Scartezzini, "A generalised stochastic model for the simulation of occupant presence," Energy and Buildings, vol. 40, pp. 83-98, 2008.

[45] C. Wang, D. Yan, and Y. Jiang, "A novel approach for building occupancy simulation," in Building simulation, 2011, pp. 149-167.

[46] C. Peng, D. Yan, R. Wu, C. Wang, X. Zhou, and Y. Jiang, "Quantitative description and simulation of human behavior in residential buildings," in Building Simulation, 2012, pp. 85-94.

[47] W. O'Brien, K. Kapsis, and A. K. Athienitis, "Manually-operated window shade patterns in office buildings: a critical review," Building and environment, vol. 60, pp. 319-338, 2013.

[48] O. A. Seppanen and W. J. Fisk, "Some Quantitative Relations between Indoor Environmental Quality and Work Performance or Health," ed, 2006.

[49] I. Richardson, M. Thomson, and D. Infield, "A high-resolution domestic building occupancy model for energy demand simulations," Energy and Buildings, vol. 40, pp. 1560-1566, 2008.

[50] K. P. Lam, M. Höynck, B. Dong, B. Andrews, Y.-S. Chiou, R. Zhang, D. Benitez, and J. Choi, "Occupancy detection through an extensive environmental sensor network in an open-plan office building," IBPSA Building Simulation, pp. 1452-1459, 2009.

[51] E. Hailemariam, R. Goldstein, R. Attar, and A. Khan, "Real-time occupancy detection using decision trees with multiple sensor types," presented at the Proceedings of the 2011 Symposium on Simulation for Architecture and Urban Design, Boston, Massachusetts, 2011.

[52] C. C. Federspiel, "Estimating the inputs of gas transport processes in buildings," Control Systems Technology, IEEE Transactions on, vol. 5, pp. 480-489, 1997.

[53] S. Wang and X. Jin, "CO2-based occupancy detection for on-line outdoor air flow control," Indoor and Built Environment, vol. 7, pp. 165-181, 1998.

[54] E. Hailemariam, R. Goldstein, R. Attar, and A. Khan, "Real-time occupancy detection using decision trees with multiple sensor types," in Proceedings of the 2011 Symposium on Simulation for Architecture and Urban Design, 2011, pp. 141-148.

[55] H. Burak Gunay, W. O'Brien, and I. Beausoleil-Morrison, "Development of an occupancy learning algorithm for terminal heating and cooling units," Building and environment.

[56] M. Trivedi, K. Huang, and I. Mikic, "Intelligent environments and active camera networks," in Systems, Man, and Cybernetics, 2000 IEEE International Conference on, 2000, pp. 804-809.

[57] L. Atallah, M. ElHelw, J. Pansiot, D. Stoyanov, L. Wang, B. Lo, and G.-Z. Yang, "Behaviour profiling with ambient and wearable sensing," in 4th International Workshop on Wearable and Implantable Body Sensor Networks (BSN 2007), 2007, pp. 133-138.

[58] D. Wang, E. Arens, and C. Federspiel, "Opportunities to save energy and improve comfort by using wireless sensor networks in buildings," in Third International Conference for Enhanced Building Operations, 2003.

[59] N. Saldanha and I. Beausoleil-Morrison, "Measured end-use electric load profiles for 12 Canadian houses at high temporal resolution," Energy and Buildings, vol. 49, pp. 519-530, 2012.

[60] H. Kim, M. Marwah, M. F. Arlitt, G. Lyon, and J. Han, "Unsupervised Disaggregation of Low Frequency Power Measurements," in SDM, 2011, pp. 747-758.

[61] J. Z. Kolter and M. J. Johnson, "REDD: A public data set for energy disaggregation research," in Workshop on Data Mining Applications in Sustainability (SIGKDD), San Diego, CA, 2011.

[62] M. S. Rea, "Window blind occlusion: a pilot study," Building and environment, vol. 19, pp. 133-7, 1984.

[63] B. Meerbeek, M. te Kulve, T. Gritti, M. Aarts, E. van Loenen, and E. Aarts, "Building automation and perceived control: A field study on motorized exterior blinds in Dutch offices," Building and environment, vol. 79, pp. 66-77, 2014.

[64] W. O'Brien, K. Kapsis, A. K. Athienitis, and T. Kesik, "Methodology for quantifying the performance implications of intelligent shade control in existing buildings in an urban context," presented at the SimBuild 2010, New York City, 2010. 
[65] Y. Sutter, D. Dumortier, and M. Fontoynont, "The use of shading systems in VDU task offices: A pilot study," Energy and Buildings, vol. 38, pp. 780-789, 2006.

[66] C. Lindsay and P. Littlefair, "Occupant use of Venetian blinds in offices," Building Research Establishment (BRE), vol. Contract PD233/92, Garston Library, Watford, UK, 1992.

[67] H. Rijal, P. Tuohy, M. Humphreys, J. Nicol, A. Samuel, and J. Clarke, "Using results from field surveys to predict the effect of open windows on thermal comfort and energy use in buildings," Energy and Buildings, vol. 39, pp. 823-836, 2007.

[68] S. Herkel, U. Knapp, and J. Pfafferott, "Towards a model of user behaviour regarding the manual control of windows in office buildings," Building and environment, vol. 43, pp. 588-600, 2008.

[69] R. Ooka and K. Komamura, "Optimal design method for building energy systems using genetic algorithms," Building and environment, vol. 44, pp. 1538-1544, 2009.

[70] J. S. Weilil and P. M. Gladhart, "Occupant behavior and successful energy conservation: Findings and implications of behavioral monitoring," 1990.

[71] J. Woods, "Fiddling with Thermostats: Energy Implications of Heating and Cooling Set Point Behavior," in Proceedings of the 2006 ACEEE Summer Study on Energy Efficiency in Buildings, 2006.

[72] H. B. Gunay, W. O'Brien, I. Beausoleil-Morrison, and A. Perna, "On behavioral effects of residential electricity submeterings," Building and environment, vol. (In review), 2014.

[73] T. Peffer, M. Pritoni, A. Meier, C. Aragon, and D. Perry, "How people use thermostats in homes: A review," Building and environment, vol. 46, pp. 2529-2541, 2011.

[74] J. F. Nicol, "Characterising occupant behaviour in buildings: towards a stochastic model of occupant use of windows, lights, blinds, heaters and fans," in Building Simulation, Rio de Jeneiro, August 1315, 2001, pp. 1073-1078.

[75] H. Gonçalves, A. Ocneanu, M. Bergés, and R. Fan, "Unsupervised disaggregation of appliances using aggregated consumption data," in The 1st KDD Workshop on Data Mining Applications in Sustainability (SustKDD), 2011.

[76] C. Morgan and R. de Dear, "Weather, clothing and thermal adaptation to indoor climate," Climate Research, vol. 24, pp. 267-284, 2003.

[77] G. R. Newsham, "Clothing as a thermal comfort moderator and the effect on energy consumption," Energy and Buildings, vol. 26, pp. 283-291, 1997.

[78] F. Haldi and D. Robinson, "Modelling occupants' personal characteristics for thermal comfort prediction," International Journal of Biometeorology, vol. 55, pp. 681-694, 2011/09/01 2011.

[79] F. Oldewurtel, A. Parisio, C. N. Jones, D. Gyalistras, M. Gwerder, V. Stauch, B. Lehmann, and M. Morari, "Use of model predictive control and weather forecasts for energy efficient building climate control," Energy and Buildings, vol. 45, pp. 15-27, 2012.

[80] K. Gram-Hanssen, "Residential heat comfort practices: understanding users," Building Research \& Information, vol. 38, pp. 175-186, 2010.

[81] V. Fabi, R. V. Andersen, S. Corgnati, and B. W. Olesen, "Occupants' window opening behaviour: A literature review of factors influencing occupant behaviour and models," Building and environment, vol. 58, pp. 188-198, 2012.

[82] R. V. Andersen, J. Toftum, K. K. Andersen, and B. W. Olesen, "Survey of occupant behaviour and control of indoor environment in Danish dwellings," Energy and Buildings, vol. 41, pp. 11-16, 2009.

[83] C. F. Reinhart, J. Mardaljevic, and Z. Rogers, "Dynamic daylight performance metrics for sustainable building design," Leukos, vol. 3, pp. 1-25, 2006.

[84] W. K. E. Osterhaus, "Discomfort glare assessment and prevention for daylight applications in office environments," Solar Energy, vol. 79, pp. 140-158, 2005.

[85] J. Wienold and J. Christoffersen, "Evaluation methods and development of a new glare prediction model for daylight environments with the use of CCD cameras," Energy and Buildings, vol. 38, pp. 743-757, 2006.

[86] J. A. Jakubiec and C. Reinhart, "The Use of Glare Metrics in the Design of Daylit Spaces: Recommendations for Practice," presented at the 9th International Radiance Workshop, Freiberg, Germany, 2010. 
[87] K. Konis, "The influence of occupant behavior on facade solar transmission: discrepancies between observed shade control behavior and simulation-based shade control models," ASHRAE Transactions, vol. 119, 2013/07// 2013.

[88] A. I. Rubin, B. L. Collins, and R. L. Tibbott, "Window blinds as a potential energy saver-a case study," NBS Building Science Series, vol. 112, 1978.

[89] J. Veitch, A., S. Mancini, A. D. Galasiu, and A. Laouadi, "Survey on Canadian households' control of indoor climate," National Research Council of Canada2009.

[90] L. Lutzenhiser, "Social and behavioral aspects of energy use," Annual Review of Energy and the Environment, vol. 18, pp. 247-289, 1993.

[91] H. B. Gunay, W. O'Brien, I. Beausoleil-Morrison, and A. Perna, "On behavioral effects of residential electricity submetering," Building and environment, vol. 81, pp. 396-403, 2014.

[92] P. O. Fanger, Thermal comfort: Analysis and applications in environmental engineering. Berkeley, CA: McGraw-Hill, 1970.

[93] K. G. Van Den Wymelenberg, "Evaluating Human Visual Preference and Performance in an Office Environment Using Luminance-based Metrics," 2013.

[94] L. Berkowitz and E. Donnerstein, "External validity is more than skin deep: Some answers to criticisms of laboratory experiments," American psychologist, vol. 37, p. 245, 1982.

[95] J. A. List and S. D. Levitt, "What do laboratory experiments tell us about the real world," NBER Working Paper, 2005.

[96] W. O'Brien and H. B. Gunay, "The contextual factors contributing to occupants' adaptive comfort behaviors in offices-A review and proposed modeling framework," Building and environment, vol. 77, pp. 77-87, 2014.

[97] G. S. Brager and R. J. de Dear, "Thermal adaptation in the built environment: a literature review," Energy and Buildings, vol. 27, pp. 83-96, 1998.

[98] F. Haldi, "A probabilistic model to predict building occupants'diversity towards their interactions with the building envelope," presented at the Building Simulation Chambery, France Aug. 26-29, 2013.

[99] S. Karjalainen, "Gender differences in thermal comfort and use of thermostats in everyday thermal environments," Building and environment, vol. 42, pp. 1594-1603, 2007.

[100] K. C. Parsons, "The effects of gender, acclimation state, the opportunity to adjust clothing and physical disability on requirements for thermal comfort," Energy and Buildings, vol. 34, pp. 593599, 2002.

[101] P. R. Boyce, Human Factors in Lighting, Third Edition: Taylor \& Francis, 2014.

[102] C. Stangor, Research Methods for the Behavioral Sciences: Cengage Learning, 2014.

[103] G. Diaper, "The Hawthorne effect: A fresh examination," Educational Studies, vol. 16, pp. 261-267, 1990.

[104] X. Zhou, D. Yan, T. Hong, and X. Ren, "Data analysis and stochastic modeling of lighting energy use in large office buildings in China," Energy and Buildings, vol. 86, pp. 275-287, 2015.

[105] R. Melfi, B. Rosenblum, B. Nordman, and K. Christensen, "Measuring building occupancy using existing network infrastructure," in Green Computing Conference and Workshops (IGCC), 2011 International, 2011, pp. 1-8.

[106] S. Borgeson and G. Brager, "Occupant control of windows: accounting for human behavior in building simulation," University of California, Berkeley, 2008.

[107] R. L. Axtell, C. J. Andrews, and M. J. Small, "Agent-Based Modeling and Industrial Ecology," Journal of Industrial Ecology, vol. 5, pp. 10-13, 2001.

[108] C. J. Andrews, D. Yi, U. Krogmann, J. A. Senick, and R. E. Wener, "Designing buildings for real occupants: An agent-based approach," Systems, Man and Cybernetics, Part A: Systems and Humans, IEEE Transactions on, vol. 41, pp. 1077-1091, 2011.

[109] J. Langevin, J. Wen, and P. L. Gurian, "Including occupants in building performance simulation: Integration of an agent-based occupant behavior algorithm with EnergyPlus," 2014.

[110] J. Duffy, "Agent-based models and human subject experiments," Handbook of computational economics, vol. 2, pp. 949-1011, 2006. 
[111] X. Zhao, J. Venkateswaran, and Y.-J. Son, "Modeling human operator decision making in manufacturing systems using BDI agent paradigm," in Proc. Annu. Ind. Eng. Res. Conf, 2005, pp. 1418.

[112] A. S. Rao and M. P. Georgeff, "Decision procedures for BDI logics," Journal of logic and computation, vol. 8, pp. 293-343, 1998.

[113] H. B. Gunay, W. O'Brien, I. Beausoleil-Morrison, R. Goldstein, S. Breslav, and A. Khan, "Coupling stochastic occupant models to building performance simulation using the discrete event system specification formalism," Journal of Building Performance Simulation, vol. 7, pp. 457-478, 2014.

[114] R. Yasue, H. Habara, A. Nakamichi, and Y. Shimoda, "Modelling the occupant behavior relating to window and air condition operation based on survey results " presented at the Building Simiulation, Chambery, France, 2013.

[115] V. Inkarojrit, "Balancing comfort: Occupants' control of window blinds in private offices," PhD, Centre for the Built Environment University of California, Berkeley, Berkeley, CA, 2005.

[116] F. Haldi and D. Robinson, "Stochastic / probabilistic modelling of multiple adaptive processes: some subtle complexities," presented at the eSim Quebec City, QC, May 20-21, 2008.

[117] W. Parys, D. Saelens, and H. Hens, "Coupling of dynamic building simulation with stochastic modelling of occupant behaviour in offices-a review-based integrated methodology," Journal of Building Performance Simulation, vol. 4, pp. 339-358, 2011.

[118] Z. Yu, B. C. Fung, and F. Haghighat, "Extracting knowledge from building-related data-A data mining framework," in Building Simulation, 2013, pp. 207-222.

[119] P. Boyce, "Observations of the manual switching of lighting," Lighting Research and Technology, vol. 12, pp. 195-205, 1980.

[120] T. Inoue, T. Kawase, T. Ibamoto, S. Takakusa, and Y. Matsuo, "The development of an optimal control system for window shading devices based on investigations in office buildings," ASHRAE Transactions, vol. 94, pp. 1034-1049, 1988.

[121] I. Macdonald and P. Strachan, "Practical application of uncertainty analysis," Energy and Buildings, vol. 33, pp. 219-227, 2001.

[122] R. Fritsch, A. Kohler, M. Nygård-Ferguson, and J. L. Scartezzini, "A stochastic model of user behaviour regarding ventilation," Building and environment, vol. 25, pp. 173-181, // 1990.

[123] D. J. Bourgeois, "Detailed occupancy prediction, occupancy-sensing control and advanced behavioural modelling within whole-building energy simulation," PhD Thesis, University of Laval, Quebec, 2005.

[124] C. Liao, Y. Lin, and P. Barooah, "Agent-based and graphical modelling of building occupancy," Journal of Building Performance Simulation, vol. 5, pp. 5-25, 2012.

[125] S. Chang and A. Mahdavi, "A Hybrid System for Daylight Responsive Lighting Control," Journal of the Illuminating Engineering Society, vol. 31, pp. 147-157, 2002/01/01 2002.

[126] J. Fenn and M. Raskino, Mastering the hype cycle: how to choose the right innovation at the right time: Harvard Business Press, 2008.

[127] D. Watts, Everything is obvious: once you know the answer. New York, NY: Crown Publishing Group, Random House, 2011.

[128] S. B. Hulley, S. R. Cummings, W. S. Browner, D. G. Grady, and T. B. Newman, Designing clinical research: Lippincott Williams \& Wilkins, 2013.

[129] W. A. Oleckno and B. Anderson, Essential epidemiology: principles and applications: Waveland, 2002.

[130] M. Wetter, "Co-simulation of building energy and control systems with the Building Controls Virtual Test Bed," Journal of Building Performance Simulation, vol. 4, pp. 185-203, 2011.

[131] D. Robinson, U. Wilke, and F. Haldi, "Multi agent simulation of occupants' presence and behavior," in Proceedings of Building Simulation, 2011.

[132] T. Nouidui, M. Wetter, and W. Zuo, "Functional mock-up unit for co-simulation import in EnergyPlus," Journal of Building Performance Simulation, vol. 7, pp. 192-202, 2014.

[133] D. Yan, J. Xia, W. Tang, F. Song, X. Zhang, and Y. Jiang, "DeST-An integrated building simulation toolkit Part I: Fundamentals," in Building Simulation, 2008, pp. 95-110. 
[134] T. Hong, S. D'Oca, W. JN Turner, S. C Taylor-Lange, "An ontology to represent energy-related occupant behavior in buildings. Part I: Introduction to the DNAs Framework," Building and Environment, in press, 2015. 